Laporan Kasus

\title{
Ekstraksi benda asing gigi palsu di esofagus dengan esofagotomi servikal
}

\author{
Arie Cahyono, Bambang Hermani, Fachri Hadjat, Sukri Rahman \\ Departemen Telinga Hidung Tenggorok-Bedah Kepala Leher \\ Fakultas Kedokteran Universitas Indonesia/ RS. Dr. Cipto Mangunkusumo
}

\begin{abstract}
ABSTRAK
Latar Belakang: Benda asing di esofagus harus sesegera mungkin dikeluarkan dalam kondisi yang optimal untuk mencegah terjadinya komplikasi. Esofagoskopi adalah cara yang aman dan efektif untuk ekstraksi benda asing pada sebagian besar kasus, namun pada beberapa kasus tindakan esofagoskopi tidak dapat dilakukan atau gagal mengeluarkan benda asing, sehingga diperlukan tindakan bedah berupa esofagotomi. Tujuan: Kasus ini diajukan untuk mengilustrasikan teknik esofagotomi servikal sebagai penatalaksanaan benda asing esofagus. Kasus: Dilaporkan satu kasus wanita 53 tahun dengan benda asing gigi palsu di esofagus yang gagal dikeluarkan dengan esofagoskopi sehingga diperlukan tindakan esofagotomi servikal untuk mengambilnya. Penatalaksanaan: Dilakukan esofagotomi servikal setelah esofagoskopi gagal mengeluarkan benda asing. Kesimpulan: Esofagotomi servikal dilakukan untuk mengeluarkan benda asing di esofagus apabila tindakan esofagoskopi tidak dapat dilakukan atau gagal mengeluarkan benda asing.
\end{abstract}

Kata kunci : benda asing, gigi palsu, esofagus, esofagotomi servikal.

\section{ABSTRACT}

Background: Foreign body in the esophagus should be removed as soon as possible under optimal conditions to prevent complications. Esophagoscopy is a safe and effective procedure for foreign bodies removal in most cases, but in some cases esophagoscopy could not be performed or failed to extract the foreign body, necessitating surgery such as esophagotomy. Objective: To illustrate the cervical esophagotomy technique as a management of esophageal foreign bodies. Case: A 53-years old woman with a foreign body (dentures) in the esophagus that failed to be removed by esophagoscopy and need cervical esophagotomy. Management: Cervical esophagotomy was performed after esophagoscopy failed to remove the foreign body. Conclusion: Cervical esophagotomy is needed in cases of esophageal foreign body in which of esophagoscopy could not be performed or failed to remove the foreign body.

Keywords : foreign body, denture, esophagus, cervical esophagotomy

Alamat Korespondensi : Sukri Rahman, Email : sukri_rahman@yahoo.com

\section{PENDAHULUAN}

Kerusakan atau kehilangan gigi dapat mengubah penampilan seseorang serta menyebabkan gangguan mengunyah makanan. Penggantian gigi yang hilang atau rusak akibat berbagai sebab, bertujuan untuk membantu proses mengunyah makanan, memperjelas bicara dan memperbaiki penampilan. Peningkatan pemakaian gigi palsu akhir-akhir ini, diikuti juga peningkatan kejadian tertelan gigi palsu. Gigi palsu sebagai benda asing di esofagus tidak jarang terjadi. ${ }^{1}$

Diagnosis adanya gigi palsu biasanya tidak sulit, karena biasanya pasien mengeluhkan adanya riwayat tertelan sebelumnya kecuali pada 
pasien dengan gangguan mental atau gangguan kesadaran.

Sebagian besar benda asing di esofagus dapat dikeluarkan dengan esofagoskopi, baik dengan esofagoskop kaku maupun fleksibel. Pada beberapa kasus tindakan esofagoskopi tidak dapat dilakukan atau benda asing gagal dikeluarkan, sehingga diperlukan tindakan bedah berupa esofagotomi. ${ }^{1-4}$

Soepardi $\mathrm{dkk}^{5}$ melaporkan $2(11,7 \%)$ dari 17 kasus gigi palsu dikeluarkan dengan esofagotomi servikal setelah gagal dengan esofagoskopi. Shivakumar et $\mathrm{al}^{6}$ melaporkan satu dari empat pasien tertelan gigi palsu membutuhkan operasi terbuka untuk mengeluarkannya karena tersangkut di sfingter krikofaring. ${ }^{6}$ Nwaorgu et $\mathrm{al}^{1}$ melaporkan $3(13,6 \%)$ dari 22 gigi palsu di esofagus membutuhkan esofagotomi servikal untuk mengeluarkannya.

Esofagotomi merupakan teknik operasi klasik, teknik ini pertama kali dilakukan untuk mengeluarkan benda asing di esofagus oleh Goursald tahun 1738, dan secara sistematis teknik ini pertama kali diuraikan oleh Guattani tahun 1819. Tindakan ini semakin jarang dilakukan setelah ditemukannya esofagoskop. ${ }^{?}$

Indikasi esofagotomi pada benda asing di esofagus, menurut Savary dan Miller serta Terracol dan Sweet seperti dikutip Abdurrahman ${ }^{8}$ adalah: 1). Benda asing telah tersangkut di esofagus beberapa hari sehingga menyebabkan infeksi di daerah leher, indurasi dan nyeri sepanjang selubung karotis; 2). Benda asing berukuran besar dan berbentuk tidak teratur yang telah beberapa hari berada dalam esofagus; 3 ). Benda asing mempunyai bagian yang tajam; 4). Pengangkatan benda asing secara esofagoskopi gagal dan 5). Benda aing menyebabkan hematemesis hebat atau ada kecurigaan telah terjadi perforasi, baik secara klinis atau radiologis.

Esofagotomi dapat menyebabkan berbagai komplikasi berupa perdarahan, infeksi, cedera n.laringeus rekuren dan striktura esofagus. ${ }^{7}$

Kasus ini diajukan untuk mengilustrasikan teknik esofagotomi servikal sebagai penatalaksanaan benda asing esofagus.

\section{LAPORAN KASUS}

Seorang pasien wanita umur 53 tahun datang ke poliklinik Bronkhoesofagologi THT-KL RSCM pada tanggal 29 Januari 2008 setelah tertelan gigi palsu sejak 2 hari sebelumnya. Peristiwa tersebut terjadi saat pasien memasang gigi palsu yang sudah patah. Bagian yang tertelan merupakan patahan akrilik dengan lempeng penahan ke langit-langit (basis) dan kawat sangkutan ke gigi serta beberapa gigi. Sejak pemakaian gigi palsu, pasien tidak pernah kontrol ke dokter gigi, selama dua tahun terakhir. Pasien berusaha untuk mengeluarkan sendiri patahan gigi palsu namun tidak berhasil. Ada keluhan rasa mengganjal di tenggorok, nyeri menelan, tidak bisa makan tapi masih bisa minum. Tidak ada keluhan sesak nafas, batuk-batuk, rasa nyeri atau panas di dada, keluar darah dari mulut ataupun demam.

Pada pemeriksaan fisik tidak didapati tanda obstruksi jalan nafas, suhu dalam batas normal dan tidak ditemukan adanya emfisema subkutis daerah leher. Pemeriksaan tenggorok dalam batas normal.

Pada pemeriksaan Rontgen servikal anteropostenior (AP) dan lateral, tampak benda asing radioopak berdensitas metal pada retrotrakea setinggi vertebra servikal ke-7 dan torakal ke-1, trakea tak tampak kelainan. Kesimpulan terdapat benda asing berdensitas metal di retrotrakea proyeksi esofagus. (Gambar 1)

Pemeriksaan laboratorium didapatkan dalam batas normal. Konsultasi ke Penyakit Dalam untuk toleransi operasi, dinyatakan risiko ringan dan konsultasi Anestesi setuju untuk tindakan dilaksanakan dengan anestesi umum. Direncanakan tindakan esofagoskopi untuk ekstraksi benda asing menggunakan esofagoskop kaku, dengan persiapan esofagotomi.

Dilakukan foto polos servikal lateral ulang dan toraks sebelum tindakan, tanggal 31 Januari 2008 dengan kesan corpus alienum opak berbentuk kawat setinggi servikal ke-7 dan torakal ke-1, jantung dan paru dalam batas normal. Posisi benda asing dibandingkan dengan foto Rontgen sebelumnya masih tetap sama. 


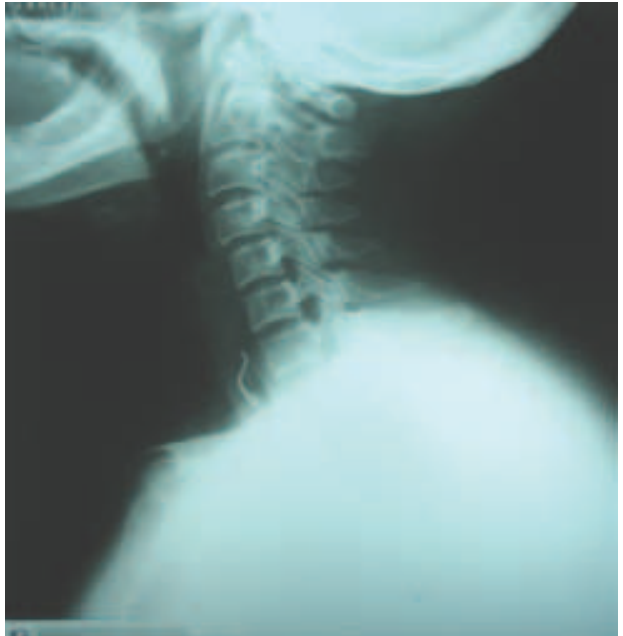

A

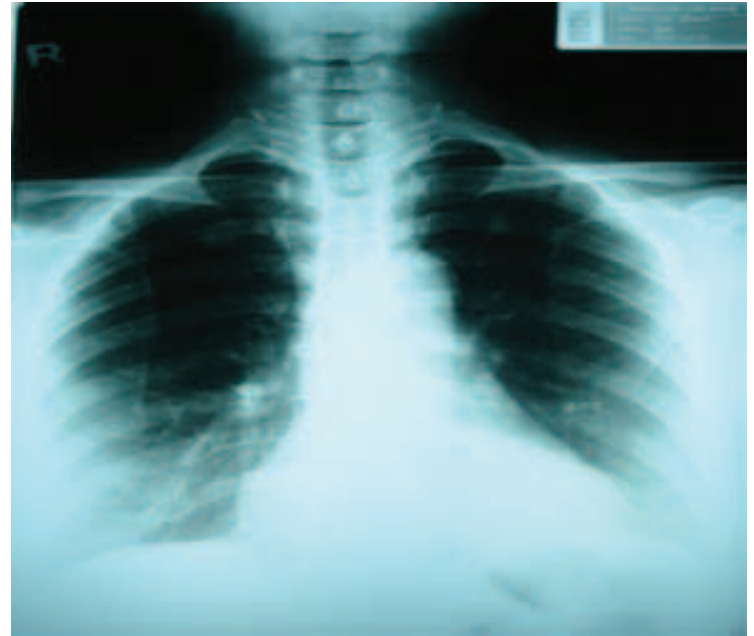

B

Gambar 1. Pemeriksaan radiologi servikal, tampak gambaran benda asing radioopak.

Tanggal 31 Januari2008 dilakukan esofagoskopi dengan esofagoskop kaku. Tampak benda asing gigi palsu pada $16 \mathrm{~cm}$ dari insisivus atas. Evaluasi dilakukan menggunakan kamera endoskop $0^{\circ}$, tampak bagian akrilik dan sebagian dari kawat. Dicoba melakukan ekstraksi akrilik menggunakan forsep, benda asing dapat tertarik sampai introitus (13 cm dari insisivus atas), ketika dicoba ekstraksi lebih lanjut, akrilik tertahan dan ujung kawat tidak terlihat. Dilakukan perasat dengan memutar posisi benda asing dengan forsep alligator secara hatihati namun tindakan sulit dilakukan karena ukuran benda asing yang cukup besar. Dicoba kembali tindakan ekstraksi namun tetap gagal. Untuk mencegah terjadinya komplikasi, diputuskan untuk melakukan esofagotomi servikal.

Dilakukan tindakan asepsis dan antisepsis daerah operasi (leher sebelah kiri). Kepala pasien dimiringkan ke kanan dan diekstensi, dibuat insisi kulit sejajar madibula setinggi kartilago krikoid (setinggi perkiraan letak benda asing) sampai subkutis. Jaringan di bawahnya dibebaskan secara tumpul, perdarahan dirawat, kelenjar tiroid disisihkan dengan memotong ismusnya dan diikat dengan benang silk. Nervus laringeus rekuren diidentidakasi. Diseksi dilanjutkan sampai trakeo-esofagus teridentifikasi dan teraba benda asing. Kemudian esofagoskop kaku dimasukan oleh asisten melalui mulut dan ujung esofagoskop diarahkan ke lateral kiri. Dengan tekhnik ini maka esofagus akan muncul di bawah trakea. Esofagus diidentifikasi dan benda asing dapat teraba di dalam lumen esofagus. Dibuat insisi vertikal kurang-lebih $2 \mathrm{~cm}$ pada dinding esofagus setinggi letak benda asing. Tampak benda asing akrilik dan gigi palsu dengan bagian kawat mengait mukosa esofagus. Dilakukan ekstraksi benda asing gigi palsu dengan tiga buah gigi ukuran 2,3 x 2,4 $\mathrm{cm}$.(Gambar 2) dan pada evaluasi esofagus tidak tampak adanya perforasi.

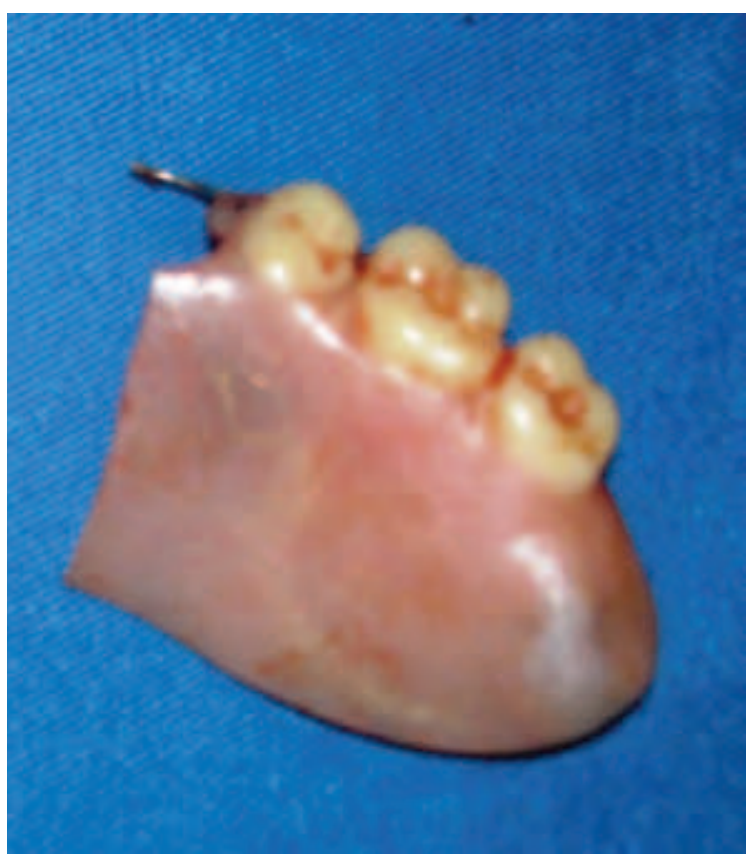

Gambar 2. Gigi palsu yang tertelan 
Selanjutnya dipasang naso-gatric tube (NGT) no.16. Dilakukan penjahitan kembali dinding esofagus dengan benang vicril 3-0 dan perdarahan dirawat. Dipasang salir Penrose sebelum luka operasi ditutup dengan penjahitan mukosa menghadap sisi lumen esofagus dan lapis demi lapis. Luka operasi ditutup perban tekan.

Setelah operasi pasien dirawat di Intensive Care Unit (ICU) dan mendapat pengobatan antibiotik golongan sefalosporin 1 × 2 gram iv, transamin iv $3 \times 500 \mathrm{mg}$, tramadol $2 \times 50 \mathrm{mg}$ iv, deksametason iv $3 \times 4 \mathrm{mg}$, ranitidin $2 \times 50 \mathrm{mg}$ iv dan diet cair melalui NGT. Keadaan pasien selama di ICU stabil, tidak ada demam. Luka operasi tenang dan tidak terdapat emfisema subkutis daerah leher. Pasien diminta untuk tidak makan dan minum melalui mulut dan tidak menelan ludah selama masih terpasang NGT.

Salir dilepas hari ketiga setelah operasi, jahitan dilepas hari ke-7. Pengobatan diganti siprofloksasin peroral $2 \times 500 \mathrm{mg}$, ranitidin tablet $2 \times 150 \mathrm{mg}$ per oral dan dan Betadin kumur. Pasien menolak untuk pemeriksaan esofagografi karena merasa tidak ada keluhan. Hari ke-11 dilakukan test minum, dengan hasil baik dan NGT dilepas. Makan dan minum bisa dilakukan seperti biasa tanpa keluhan. Hari ke-12 pasien boleh pulang dan diminta kontrol ke poliklinik Laring-Faring THT-KL satu minggu kemudian. Pada saat kontrol tidak terdapat keluhan dan tidak terdapat demam dan emfisema subkutis.

\section{DISKUSI}

Telah dilaporkan kasus seorang wanita berusia 53 tahun dengan riwayat tertelan benda asing gigi palsu di esofagus. Tertelan benda asing umumnya terjadi pada anak, namun tidak jarang terjadi pada orang dewasa. Shivakumar et $\mathrm{al}^{6}$ melaporkan dari 152 kasus tertelan benda asing $48(31,57 \%)$ terjadi pada orang dewasa, $4(8,3 \%)$ kasus di antaranya tertelan gigi palsu.

Pada kasus ini gigi palsu tertelan ketika pasien sedang memasang gigi palsu yang sudah patah sebelumnya. Pemakaian gigi palsu yang sudah patah merupakan penyebab tertelannya gigi palsu.
Naswanto $\mathrm{dkk}^{9}$ melaporkan dua kasus tertelan gigi palsu. Keduanya juga disebabkan pasien memakai gigi palsu yang sudah patah. Hal yang sama juga dilaporkan Marbun, ${ }^{3} 8$ dari 18 kasus gigi palsu di esofagus terjadi karena pemakaian gigi palsu yang sudah patah. Kecerobohan pasien merupakan penyebab yang sering dilaporkan sebagai penyebab tertelannya gigi palsu. ${ }^{1,3}$

Pemeriksaan radiologi pada pasien ini memastikan benda asing masih tersangkut di esofagus dengan gambaran kawat logam, namun pemeriksaan radiologi tidak dapat memberikan gambaran ukuran dan bentuk benda asing karena basis gigi palsu terbuat dari akrilik yang bersifat radiolusen. Benda asing tersangkut pada setinggi C7-Th1, merupakan tempat yang sering karena terdapat penyempitan fisiologis setinggi sfingter krikofaring. Nwaorgu et $\mathrm{al}^{1}$ melaporkan sebagian besar gigi palsu $(63,6 \%)$ tersangkut di esofagus proksimal (antara krikofaring dengan toraks). Hal yang berbeda dilaporkan oleh Marbun, ${ }^{3}$ yang melaporkan sebagian besar $(41,2 \%)$ gigi palsu tersangkut di esofagus torakal.

Pemeriksaan radiologi dengan kontras pada kasus gigi palsu radiolusen di esofagus sering tidak membantu. ${ }^{3,10}$ Marbun $^{3}$ melaporkan dari 2 kasus gigi palsu radiolusen yang dilakukan pemeriksaan radiologi dengan kontras, tetap tidak dapat memperkirakan letak gigi palsu. Hal ini terjadi karena bahan gigi palsu mencegah melekatnya kontras (barium).

Pada pasien ini dilakukan tindakan esofagoskopi dengan esofagoskop kaku, dengan persiapan esofagotomi servikal jika benda asing gagal diekstraksi. Persiapan esofagotomi telah dilakukan sebelum operasi, karena adanya bagian tajam (kawat) yang mungkin tersangkut.

Gigi palsu tidak berhasil dikeluarkan dengan esofagoskopi karena ada bagian benda asing yang menancap di mukosa esofagus. Manuver benda asing sulit dilakukan karena ukuran benda asing yang cukup besar. Untuk mencegah terjadinya komplikasi, diputuskan untuk dilakukan esofagotomi servikal. Benda asing berhasil dikeluarkan, dan tampak bahwa bagian yang 
menyebabkan benda asing tertahan adalah kaitan kawat gigi ke mukosa esofagus.

Esofagotomi untuk mengeluarkan gigi palsu di esofagus adalah tindakan yang tidak jarang dilakukan, Nwaorgu et al $^{1}$ melaporkan 3 dari $22(13,6 \%)$ gigi palsu di esofagus membutuhkan esofagotomi servikal untuk mengeluarkannya. Soepardi $\mathrm{dkk}^{5}$ melaporkan 2 dari $17 \quad(11,7 \%)$ kasus gigi palsu diekstraksi dengan esofagotomi servikal setelah gagal dengan esofagoskopi. Shivakumar et $\mathrm{al}^{6}$ melaporkan satu dari 4 (25\%) pasien tertelan gigi palsu membutuhkan operasi terbuka untuk mengeluarkannya karena tersangkut di sfingter krikofaring. ${ }^{1,5,6}$

Esofagotomi dilakukan berdasarkan letak tersangkutnya benda asing, dapat berupa esofagotomi servikal, transtorakal atau transabdominal. Esofagotomi servikal dimulai dengan membuat insisi kulit setinggi kartilago krikoid pada sisi tempat benda asing lebih mudah dicapai atau daerah dengan tanda abses. Insisi dapat dibuat melintang atau mengikuti sisi depan m. sternokleidomastoideus. Setelah insisi kulit, m.sternokleidomastoideus diidentifikasi dan disisihkan ke samping. Ismus kelenjar tiroid dipotong dan diikat atau disisihkan ke samping. Jaringan dibebaskan secara tumpul sampai trakea teridentifikasi, dan selanjutnya esofagus diidentifikasi secara tumpul. Bila esofagus teraba dan benda asing dapat dipastikan lokasinya, esofagus diinsisi secara vertikal, untuk menghindari cedera n. laringeus rekuren yang terletak di cekungan trakeoesofagus. Insisi sebaiknya dibuat lebih ke posterior, selanjutnya benda asing dikeluarkan. Pipa nasogastrik (NGT) dipasang untuk nutrisi. Dinding esofagus dijahit dengan benang yang bisa diserap (vicril 3-0) dengan mukosa menghadap ke dalam lumen esofagus. Setelah luka ditutup, dipasang salir (drain), luka insisi dijahit lapis demi lapis. Luka operasi ditutup dengan perban tekan. Pasca tindakan diberikan antibotika dosis tinggi aerob dan anaerob untuk mengatasi infeksi dan kortikosteroid untuk mengatasi inflamasi. Selama NGT masih terpasang pasien diminta tidak menelan ludah untuk mempermudah penyembuhan luka dan mencegah terjadinya fistel. $7,8,11$

Pasca tindakan pasien ini mendapat terapi antibiotik, kortikosteroid dan analgetik. Diet diberikan melalui NGT. Untuk mempercepat penyembuhan luka serta mencegah terjadinya fistel pasien diminta untuk tidak menelan ludah. Selama perawatan dan saat kontrol setelah pulang tidak ditemukan keluhan, dan pasien dapat makan minum seperti biasa. Tidak terdapat suara serak. Tidak ditemukan tanda-tanda adanya komplikasi. ${ }^{7,8}$

Untuk mengetahui ada tidaknya fistel atau perforasi pada esofagus diperlukan pemeriksaan esofagografi pasca tindakan, namun pasien menolak karena merasa tidak ada keluhan. Secara kilinis tidak ditemukan adanya tanda perforasi berupa trias gejala klasik: nyeri, demam dan emfisema subkutis. ${ }^{12}$

Tindakan esofagotomi servikal pada kasus ini dilakukan untuk mengeluarkan benda asing di esofagus yang gagal dikeluarkan secara esofagoskopi. Dengan tindakan ini, komplikasi yang berbahaya dapat dihindari.

\section{DAFTAR PUSTAKA}

1. Nwaorgu OG, Onakoya PA, Sogebi OA, Kokong DD, Dosumu OO, et al. Esophageal Impacted Dentures. J Nation Med Assoc 2004; 96:1350- 3.

2. Chee LWJ, Sethi DS. Diagnostic and therapeutic approach to migrating fereign bodies. Ann Otol Rhinol Laryngol 1999; 108:177-80.

3. Marbun EM. Aspek klinis benda asing gigi tiruan di esofagus. [Tesis]. Jakarta: FKUI; 1991.

4. Blair SR, Graeber GM, Cruzzapala JL, Gustafson RA, Hill RC. Current management of esophageal impactions. Chest 1993; 104:1205-9

5. Soepardi E, Iskandar N, Yunizaf MH, Penaggulangan benda asing dalam esofagus. ORL Indonesiana 1982; 14:111-6.

6. Shivakumar AM, Naik AS, Prashanth KB, Hongal GF, Chaturvedy G. Foreign body in upper digestive tract. Indian J Otolaryngol 2006; 58:63-8.

7. Truesdale PE. Oesophagotomy for foreign bodies in the oesophagus. Ann Surg 1924; 80:375-82.

8. Abdurrahman H, Jusuf M. Ekstraksi benda asing di 
esofagus dengan esofagotomi. ORL Indonesiana 1986; 17:29-34.

9. Naswanto, Yunizaf MH, Hadjat F, Hermani B. The removal of denture foreign body in the esophagus by open esophagostomy. ORL Indonesiana 1994; 25:355-8.

10. Hashmi S, Walter J, Smith W, Latis S. Swallowed partial dentures. J Royal Med 2004; 97:72-5.
11. Knoefel WT, Schmelzle R. Cervical Esophagectomy (step 1) in: Clavien PA, Sarr MG, Fong Y, eds. Atlas of Upper Gastrointestinal and Hepato pancreato biliary surgery. Berlin, Heidelberg: Springer; 2007. p. 47-54.

12. Shaligram A, Dugar N, Capper R. Perforation of cervical oesophagus. J Laryngol Otol 2005; 119:5-3. 